ARTIFICIAL SATELLITES, Vol. 48, No. $3-2013$
DOI: $10.2478 /$ arsa-2013-0010

\title{
ANALYSIS OF CURRENT POSITION DETERMINATION ACCURACY IN NATURAL RESOURCES CANADA PRECISE POINT POSITIONING SERVICE
}

\author{
Grzegorz Krzan, Karol Dawidowicz, Krzysztof Świątek \\ University of Warmia and Mazury in Olsztyn, Faculty of Geodesy and Land Management, \\ Institute of Geodesy, 10-719 Olsztyn, ul. Oczapowskiego 1 \\ g.krzan@gmail.com,karol.dawidowicz@uwm.edu.pl,krzysztof.swiatek@uwm.edu.pl
}

\begin{abstract}
Precise Point Positioning $(P P P)$ is a technique used to determine highprecision position with a single GNSS receiver. Unlike DGPS or RTK, satellite observations conducted by the $P P P$ technique are not differentiated, therefore they require that parameter models should be used in data processing, such as satellite clock and orbit corrections. Apart from explaining the theory of the $P P P$ technique, this paper describes the available web-based online services used in the post-processing of observation results. The results obtained in the post-processing of satellite observations at three points, with different characteristics of environment conditions, using the CSRS-PPP service, will be presented as the results of the experiment. This study examines the effect of the duration of the measurement session on the results and compares the results obtained by working out observations made by the GPS system and the combined observations from GPS and GLONASS. It also presents the analysis of the position determination accuracy using one and two measurement frequencies.
\end{abstract}

Key words: Satellite geodesy, PPP, CSRS, GPS, GLONASS

\section{INTRODUCTION}

Currently, differential techniques are the most commonly-used method in geodesic measurements in countries with well-developed reference station infrastructure. Their high precision is ensured by corrections calculated with the use of GNSS receivers at reference stations which are broadcast in real time to the user's receiver, or taken into account at the post-processing stage. Due to the high costs of establishing and maintaining a network of permanent stations, as well as the fact that highly precise satellite orbits, clock corrections and atmospheric products are made available by such centres as the International GNSS Service (IGS), the Center for Orbit Determination for Europe (CODE) and the Jet Propulsion Laboratory (JPL), many research programmes studying the PPP (Precise Point Positioning) technique have been undertaken in recent years (Alcay et al., 2012).

The $P P P$ technique uses observations from a single GNSS receiver, which can achieve a precision in the order of several centimetres (Mireault et al., 2012; Bisnath et al., 2003). However, observations from a base station are not used, which prevents the distance from the station from restricting the range of measurements made by the user (Huber et al., 2010; Rizos 
2010). On the other hand, an absence of differentiation of observations necessitates using precise satellite orbits and clock corrections in the post-processing of results as well as modelling iono- and tropospheric refractions, solid earth and ocean tides, antenna phasecenter offsets and variations, carrier-phase wind-up, relativistic effects, etc. (Mireault et al., 2012). The impact of these factors is determined from continuous satellite observations by those services (e.g. solid earth and ocean tides) or by laboratory tests (antenna phase-center offsets and variations, carrier-phase wind-up). The ambiguity of phase measurements is also a certain barrier. As a standard, the $P P P$ technique employs a float-type solution, which requires long observations (over 20 minutes) to achieve a precision of several centimetres. It is expected that the time will be reduced significantly when signals from the Galileo and Beidou systems are used in satellite measurements (Rizos et al., 2012). This should happen owing to the possibility of creating additional linear combinations of code and phase observations, based on 3-5 different frequencies. Linear combinations of phase and code measurements, created now with the use of two frequencies, allow for elimination from a measurement of the ionospheric refraction effect and the real-valued carrier phase ambiguity terms estimated from the measurement model (Bisnath et al., 2008).

The theoretical foundations of the PPP method were formulated by Zumberge et al. (1997). The observational equations for code and phase measurements, made at two frequencies, have the following form (Hofmann-Wellenhof et al., 2008):

where:

$$
\begin{gathered}
P=\rho+c d t_{r}+c d t_{b}+\Delta_{\text {trp }}+\Delta_{i o n}+\varepsilon \\
\phi=\rho+c d t_{r}+c d t_{b}+\lambda N+\Delta_{\text {trp }}-\Delta_{i o n}+\varepsilon
\end{gathered}
$$

$P$ - pseudo-range between satellite and receiver;

$\Phi$ - difference between the phases of signals in the moment $t$;

$\rho$ - geometric distance between satellite and receiver;

$c$ - speed of light;

$d t_{r}$ - difference between time of signal transmission and signal reception;

$d t_{b}$ - difference between satellite and receiver clock biases;

$\Delta_{\text {trp }}$ - tropospheric delay;

$\Delta_{\text {ion }}$ - ionospheric delay;

$\lambda$ - wavelength;

$N$ - phase ambiguity;

$\varepsilon$ - other errors.

The process of determination of coordinates of a receiver in the PPP method employs ephemeris corrections determined with a high precision and satellite clock corrections to reduce their effect on the post-processing results. Subsequently, if a measurement is made with a two-frequency receiver, an ionosphere-free linear combination is used (Cai et al., 2007; Kouba et al., 2001):

- for code measurements:

$$
P_{I F}=\frac{P_{1} f_{1}^{2}-P_{2} f_{2}^{2}}{f_{1}^{2}-f_{2}^{2}}=\rho+c d t_{r}+\Delta_{t r p}
$$

- for phase measurements:

$$
\phi_{I F}=\frac{\lambda_{1} \phi_{1} f_{1}^{2}-\lambda_{2} \phi_{2} f_{2}^{2}}{f_{1}^{2}-f_{2}^{2}}=\rho+c d t_{r}+\Delta_{t r p}+\frac{\lambda_{1} N_{1} f_{1}^{2}-\lambda_{2} N_{2} f_{2}^{2}}{f_{1}^{2}-f_{2}^{2}}
$$

The ionosphere-free linear combination makes it possible to completely eliminate the first order ionosphere delay. Therefore, unknown parameters to be determined in the equations include: the position of a receiver contained in $\rho$, receiver clock offset, tropospheric refraction delay $\Delta_{t r p}$ and the value of the ambiguity of phase measurements $N$. However, the 
combination is considerably noised due to an increase in the effect of the multi-path nature and the receiver errors on the measurement results (Van Der Marel et al., 2012).

If a measurement is performed at one frequency, it is impossible to create an ionospherefree linear combination. The effect of the ionosphere in such cases is reduced by one of two methods:

- with a linear combination of frequency $L 1$ for code and phase measurements:

$$
\phi_{I F}=0.5 \cdot P_{1}+0.5 \cdot \phi_{1}=\rho+c d t_{r}+\Delta_{t r p}+\frac{1}{2} \lambda_{1} N_{1}+\varepsilon
$$

which eliminates the tropospheric delay and reduces the noises of code observations by half;

- with the ionospheric delays determined from ionospheric maps, e.g. GIM (Global Ionosphere Maps) developed by IGS.

Slant tropospheric delay is expressed as a function of the Zenith Tropospheric Delay (ZTD) (which is an estimated parameter in the PPP method) with the use of the mapping function (Stępniak et al., 2012).

\section{ONLINE PPP SERVICES}

Web-based $P P P$ services provide a quick, practical alternative for software used for the postprocessing of satellite observations by a user. Post-processing of measurements in online services is done automatically and a user only needs to set the basic post-processing parameters and upload a file in the RINEX format. Individual services differ mainly in processing algorithms, the origin of the error models used in post-processing as well as the form of making the processing results available. The most popular $P P P$ services are:

- APPS provided by JPL California Institute of Technology (https://apps.gdgps.net/), which uses models of orbits and clock corrections from its own system JPL's GDGPS; RINEX files can be uploaded to the service from the Internet site or uploaded to the FTP server; after the results have been processed, the coordinates are provided in the ITRF2008 system; the service allows users to perform the post-processing of static and kinematic observations at two frequencies; observations from the GLONASS system are not used in post-processing;

- CSRS-PPP provided by Natural Resources Canada (http://www.geod.nrcan.gc.ca/), which uses models of orbits and clock corrections developed by the IGS services; RINEX or CompactRINEX files can be uploaded from the website or through the PPP Direct software, made available by the service; after post-processing, the user receives not only the coordinates and their sigmas in the ITRF2008 or NAD83 system, but also diagrams of the visibility of satellites, the temporal convergence of coordinates, estimated tropospheric delay and clock offset as well as detailed observational data from each measurement epoch, etc. CSRS-PPP allows for post-processing static and kinematic observations, as well as using observations from the GLONASS system;

- other services, such as: GAPS v5.0 (http://gaps.gge.unb.ca/indexv2.php), AUSPOS- Online GPS Processing Service (http://ga.gov.au/bin/gps.pl), Trimble CenterPoint RTX (http://trimblertx.com/).

\section{METHODOLOGY}

The post-processing of observations for this paper was performed with the use of the CSRS-PPP (V 1.05 03812) service, which enables a quick, practical method of uploading RINEX files by means of the PPP Direct program. The service was chosen because of the form of results provided, which allows for detailed analysis of the course of post-processing and for including measurements from the GLONASS system in post-processing. The post- 
processing covered round-the-clock observations made over three consecutive days at 3 points with different characteristics of horizon visibility. Observations made at the KROL reference station of the ASG-EUPOS system in Olsztyn (Poland) were taken as measurements at point $\mathrm{A}$, assuming that this is the point with the optimum conditions for observations, which is a consequence of a totally unobscured horizon. Points B and C were marked near typical rural built-up areas, single trees and other objects which reduce the number of visible satellites and favour the multi-path effect (Fig. 1 and 2).

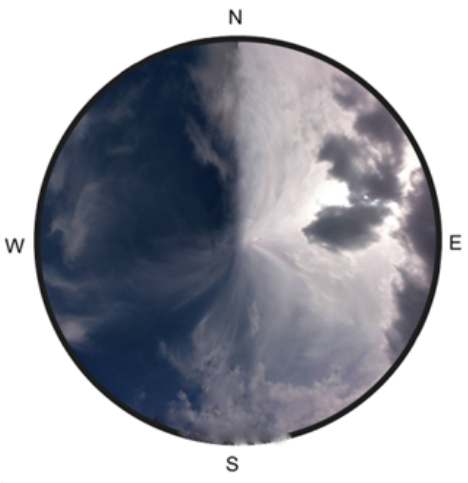

A

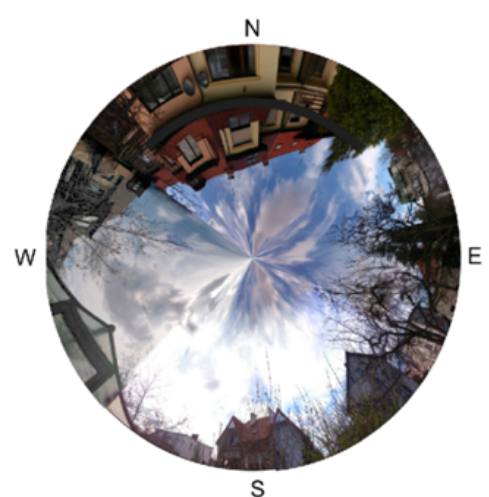

B

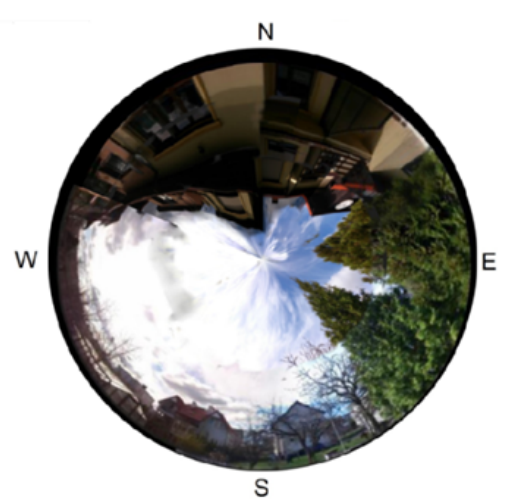

C

Fig. 1. Horizon visibility from points A, B, C

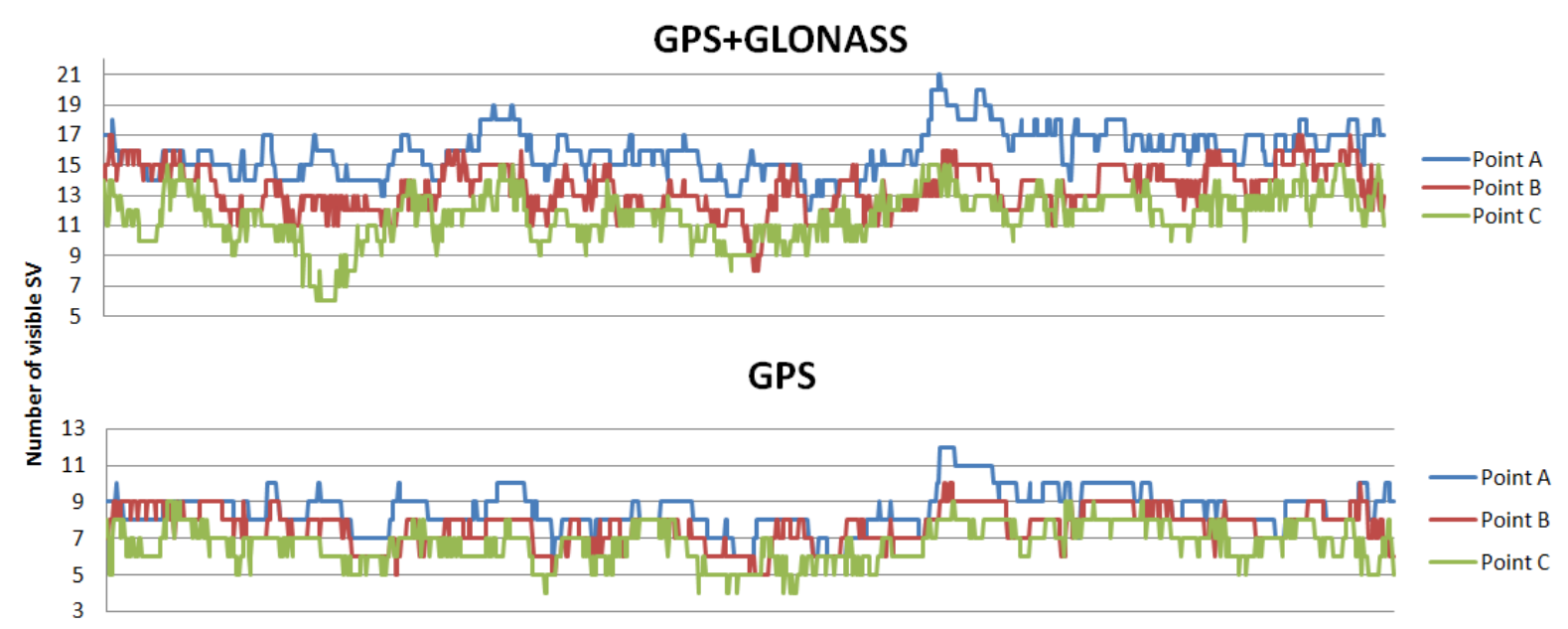

Fig. 2. Daily changes of satellite visibility at points A, B, C during the observations

The effect of terrain obstacles on the visibility of satellites can be seen in this diagram. In extreme cases, the number of the satellites observed at point $\mathrm{A}$ is up to three times larger than at point $\mathrm{C}$ during the same measurement epoch. The average number of satellites observed at points $\mathrm{A}, \mathrm{B}$ and $\mathrm{C}$ was $15,13,11$ for variant $G P S+G L O N A S S$ and 8, 7, 6 for variant $G P S$, respectively.

Measurements at the KROL station were performed with a Javad TRE_G3TH Sigma receiver with $J A V \_G R A N T-G 3 T J A V C$ antenna (www.asgeupos.pl), while at points B and C with a Topcon HiperPRO receiver with TPSHIPER_PLUS antenna.

72 hours of observations performed with a 1-second interval were divided into 4 time variants $(0.5 \mathrm{~h}, 1 \mathrm{~h}, 2 \mathrm{~h}, 4 \mathrm{~h})$ and into 4 variants depending on the observed signals (observations 
at frequencies $L 1$ and $L 1+L 2$ and using signals from the GPS and GPS+GLONASS systems), with the use of the TEQC software and the author's own scripts, written in the C\# language. This produced: 144 half-hour sessions, 72 hour-long sessions, 36 two-hour sessions and 18 four-hour sessions. Post-processing was performed with the use of the most precise "final" IGS products; results were obtained in the ITRF2008 frame and in UTM geographic coordinate system. Table 1 contains the most important NRCan PPP software processing options and parameters.

Tab. 1. NRCan PPP software processing options and parameters (source: http://www.geod.nrcan.gc.ca/)

\begin{tabular}{|c|c|c|}
\hline Option & L1 & L1\&L2 \\
\hline \multicolumn{3}{|c|}{ User Selected } \\
\hline User dynamics & Static or Kinematic & Static or Kinematic \\
\hline Reference frame & ITRF or $N A D 83(C S R S)$ & ITRF or $N A D 83(C S R S)$ \\
\hline \multicolumn{3}{|c|}{ From RINEX Header } \\
\hline Frequency observed & \multicolumn{2}{|c|}{ as defined by the RINEX RECORD '\# / TYPES OF OBSERV' } \\
\hline Marker to ARP distance & \multicolumn{2}{|c|}{ as defined by the RINEX RECORD 'ANTENNA: DELTA H/E/N' } \\
\hline Type of Antenna & \multicolumn{2}{|c|}{ as defined by the RINEX RECORD 'ANT \# / TYPE' } \\
\hline \multicolumn{3}{|c|}{ Preset by application } \\
\hline Observation processed & Code & Code and Phase \\
\hline Satellite orbits & Precise & Precise \\
\hline Satellite clocks & 5 -minute $(*)$ & 5-minute $(*)$ \\
\hline Ionospheric model & IONEX & $\mathrm{L} 1$ and L2 \\
\hline Marker coordinates & Estimated & Estimated \\
\hline Tropospheric delay & Modeled & Estimated \\
\hline Clock interpolation & Yes & Yes \\
\hline Parameter smoothing & No & Yes if kinematic \\
\hline Coordinate system & Ellipsoidal & Ellipsoidal \\
\hline Pseudorange A-PRIORI sigma & $2.000 \mathrm{~m}$ & $2.000 \mathrm{~m}$ \\
\hline Carrier phase A-PRIORI sigma & $0.100 \mathrm{~m}$ & $0.010 \mathrm{~m}$ \\
\hline Cutoff elevation & $10.000 \mathrm{deg}$ & $10.000 \mathrm{deg}$ \\
\hline
\end{tabular}

An analysis of the results presented in this paper shows differences of coordinates (northing, easting, elevation) for different variants of post-processing. The aim of the work was to attempt to determine the usability of the PPP method in geodesic measurements.

\section{THE RESULTS OF THE EXPERIMENT}

The following Tables and diagrams show the results of post-processing for different variants of elaborations. The horizontal coordinates of points are presented in the Universal Transverse Mercator (UTM) system of zone 34U (scale factor: 0.99961396) (Fig. 3, 5, 7, 9, 11, 13). Table 2 presents observational statistic (number of processed observations and observations rejected) for each variants. Because of the very large number of sessions in individual variants Table 2 contains only the mean values. The large number of rejected observations on point $\mathrm{A}$ is probably due to the fact that for ASG-EUPOS stations the $0^{\circ}$ degrees elevation cutoff angle is adopted. Points B and C were measured with $10^{\circ}$ degrees cutoff angle - the same as in CSRS service is adopted. There is also visible that generally there are not differences in the number of observations processed or rejected when $\mathrm{L} 1+\mathrm{L} 2$ and L1 variants are compared. It is 
probably due to the fact that when L1+L2 observations are used the so called L3 observations are created (and these are counted in the statistics).

Tables 3 and 4 present standard deviations and the maximum deviations of coordinates from their real values, which are adopted as average coordinates from three 24-hour solutions obtained from the most precise variant (GPS+GLONASS; $L 1+L 2)$.

Tab. 2. Observational statistic for all processing variants.

\begin{tabular}{|c|c|c|c|c|c|c|c|}
\hline \multirow[b]{2}{*}{$\begin{array}{c}\text { Processing } \\
\text { variant }\end{array}$} & \multirow[b]{2}{*}{$\begin{array}{c}G N S S \\
\text { system }\end{array}$} & \multicolumn{2}{|c|}{ Point A } & \multicolumn{2}{|c|}{ Point B } & \multicolumn{2}{|c|}{ Point C } \\
\hline & & $\begin{array}{c}\text { Processed } \\
\text { obs. }\end{array}$ & $\begin{array}{c}\text { Rejected } \\
\text { obs. }\end{array}$ & $\begin{array}{c}\text { Processed } \\
\text { obs. }\end{array}$ & $\begin{array}{l}\text { Rejected } \\
\text { obs. }\end{array}$ & $\begin{array}{c}\text { Processed } \\
\text { obs. }\end{array}$ & $\begin{array}{c}\text { Rejected } \\
\text { obs. }\end{array}$ \\
\hline & & \multicolumn{6}{|c|}{$0.5 \mathrm{~h}$ sessions } \\
\hline \multirow{2}{*}{$\begin{array}{c}\text { GPS+GLONASS } \\
L 1+L 2\end{array}$} & GPS & 15215 & 5228 & 13418 & 782 & 11791 & 904 \\
\hline & GLONASS & 13336 & 2896 & 10637 & 415 & 8932 & 328 \\
\hline \multirow{2}{*}{$\begin{array}{c}\text { GPS }+G L O N A S S \\
L 1\end{array}$} & $G P S$ & 15215 & 5228 & 13895 & 298 & 12399 & 296 \\
\hline & GLONASS & 13338 & 2894 & 10963 & 84 & 9251 & 9 \\
\hline$G P S L 1+L 2$ & $G P S$ & 15214 & 5228 & 13416 & 782 & 11794 & 904 \\
\hline \multirow[t]{2}{*}{ GPS L1 } & GPS & 15215 & 5228 & 13899 & 298 & 12402 & 296 \\
\hline & & \multicolumn{6}{|c|}{$1.0 \mathrm{~h}$ sessions } \\
\hline \multirow{2}{*}{$\begin{array}{c}G P S+G L O N A S S \\
L 1+L 2\end{array}$} & GPS & 30413 & 10461 & 26833 & 1567 & 23565 & 1806 \\
\hline & GLONASS & 26675 & 5770 & 21279 & 818 & 17859 & 662 \\
\hline \multirow{2}{*}{$\begin{array}{c}\text { GPS }+G L O N A S S \\
L 1\end{array}$} & GPS & 30413 & 10461 & 27787 & 601 & 24775 & 597 \\
\hline & GLONASS & 26678 & 5767 & 21383 & 175 & 17872 & 17 \\
\hline$G P S L 1+L 2$ & GPS & 30413 & 10461 & 26829 & 1571 & 23569 & 1808 \\
\hline \multirow[t]{2}{*}{ GPS L1 } & GPS & 30413 & 10461 & 27795 & 601 & 24779 & 597 \\
\hline & & \multicolumn{6}{|c|}{$2.0 \mathrm{~h}$ sessions } \\
\hline \multirow{2}{*}{$\begin{array}{c}G P S+G L O N A S S \\
L 1+L 2\end{array}$} & GPS & 60788 & 20967 & 53654 & 3132 & 47112 & 3612 \\
\hline & GLONASS & 53330 & 11635 & 42456 & 1660 & 35659 & 1288 \\
\hline \multirow{2}{*}{$\begin{array}{c}\text { GPS }+ \text { GLONASS } \\
L 1\end{array}$} & GPS & 60788 & 20967 & 55560 & 1201 & 49518 & 1194 \\
\hline & GLONASS & 53335 & 11630 & 43756 & 339 & 36900 & 35 \\
\hline$G P S L 1+L 2$ & $G P S$ & 60788 & 20967 & 53647 & 3138 & 47106 & 3617 \\
\hline \multirow[t]{2}{*}{ GPS L1 } & GPS & 60788 & 20967 & 55575 & 1201 & 49527 & 1194 \\
\hline & & \multicolumn{6}{|c|}{$4.0 \mathrm{~h}$ sessions } \\
\hline \multirow{2}{*}{$\begin{array}{c}\text { GPS+GLONASS } \\
L 1+L 2\end{array}$} & GPS & 121544 & 41886 & 107284 & 6382 & 94335 & 7194 \\
\hline & GLONASS & 106621 & 23322 & 84819 & 3253 & 71259 & 2593 \\
\hline \multirow{2}{*}{$\begin{array}{c}\text { GPS+GLONASS } \\
L 1\end{array}$} & GPS & 121544 & 41885 & 111243 & 2372 & 99148 & 2357 \\
\hline & GLONASS & 106631 & 23311 & 87363 & 664 & 73750 & 79 \\
\hline$G P S L 1+L 2$ & GPS & 121543 & 41886 & 107263 & 6393 & 94331 & 7198 \\
\hline GPS LI & $G P S$ & 121544 & 41885 & 111279 & 2372 & 99167 & 2357 \\
\hline
\end{tabular}

The standard deviation at point $\mathrm{A}$ for half-hour measurement sessions was equal to approx. $0.03 \mathrm{~m}$ for the northing coordinate, approx. $0.06 \mathrm{~m}$ for the easting coordinate and approx. $0.06 \mathrm{~m}$ for elevation. The values for points with limited horizon visibility $(\mathrm{B}, \mathrm{C})$ are accordingly higher and they range from approx. $0.05 \mathrm{~m}$ (northing, point $\mathrm{B}$ ) to as much as $0.22 \mathrm{~m}$ (elevation, point $\mathrm{C}$ ). The maximum deviations of coordinates from the "real" value for half-hour sessions range from 0.118 to $0.233 \mathrm{~m}$ (point A), up to almost $1.4 \mathrm{~m}$ (point C). The values decrease approximately in proportion to the duration of the measurement session. Doubling the duration of a session resulted in reducing the standard deviation and the maximum deviations of coordinates from the "real" values by half. Adding observations from the GLONASS system to the post-processing decreased the standard deviation values for sessions lasting up to 2 hours, especially at point $\mathrm{C}$, but in many cases maximum deviations has increased. Extending the session duration to 4 hours in this variant did not result in any considerable improvement and in most cases even slightly worsened results. Maybe this is due to a lower accuracy of GLONASS corrections that have to be applied in post-processing. For example GLONASS precise orbits are at $10-15 \mathrm{~cm}$ and clock data at the $1.5 \mathrm{~ns}$ level of accuracy. For GPS these values are respectively: less than $5 \mathrm{~cm}$ for precise orbits and $0.1 \mathrm{~ns}$ for clock data. The problem is undoubtedly very interesting and is worthy of further study. 
Tab. 3. Standard deviations and maximum deviations for post-processing of $L 1+L 2$

\begin{tabular}{|c|c|c|c|c|c|c|c|c|c|c|}
\hline \multirow{2}{*}{\multicolumn{3}{|c|}{$L 1+L 2$}} & \multicolumn{2}{|c|}{$0.5 \mathrm{~h}$} & \multicolumn{2}{|c|}{$1 \mathrm{~h}$} & \multicolumn{2}{|r|}{$2 \mathrm{~h}$} & \multicolumn{2}{|c|}{$4 \mathrm{~h}$} \\
\hline & & & $\sigma$ & $\max \operatorname{dev}$ & $\sigma$ & $\max$ dev. & $\sigma$ & $\max \operatorname{dev}$. & $\sigma$ & $\max$ dev. \\
\hline \multirow{6}{*}{ Point A } & \multirow{2}{*}{ North } & GPS + GLONASS & 0.028 & 0.129 & 0.013 & 0.046 & 0.007 & 0.017 & 0.006 & 0.017 \\
\hline & & GPS & 0.032 & 0.118 & 0.018 & 0.046 & 0.009 & 0.024 & 0.006 & 0.012 \\
\hline & \multirow{2}{*}{ East } & GPS + GLONASS & 0.051 & 0.233 & 0.039 & 0.087 & 0.021 & 0.082 & 0.016 & 0.058 \\
\hline & & GPS & 0.068 & 0.207 & 0.036 & 0.100 & 0.017 & 0.045 & 0.010 & 0.022 \\
\hline & \multirow{2}{*}{ Height } & GPS+GLONASS & 0.053 & 0.195 & 0.031 & 0.112 & 0.023 & 0.106 & 0.020 & 0.074 \\
\hline & & GPS & 0.062 & 0.208 & 0.034 & 0.087 & 0.019 & 0.048 & 0.007 & 0.013 \\
\hline \multirow{6}{*}{ Point B } & \multirow{2}{*}{ North } & GPS + GLONASS & 0.047 & 0.226 & 0.027 & 0.134 & 0.010 & 0.027 & 0.006 & 0.018 \\
\hline & & GPS & 0.047 & 0.143 & 0.023 & 0.074 & 0.012 & 0.028 & 0.007 & 0.015 \\
\hline & \multirow{2}{*}{ East } & GPS + GLONASS & 0.095 & 0.469 & 0.054 & 0.257 & 0.027 & 0.104 & 0.016 & 0.046 \\
\hline & & GPS & 0.137 & 0.540 & 0.067 & 0.163 & 0.030 & 0.096 & 0.011 & 0.022 \\
\hline & \multirow{2}{*}{ Height } & GPS+GLONASS & 0.101 & 0.499 & 0.050 & 0.127 & 0.028 & 0.058 & 0.021 & 0.046 \\
\hline & & GPS & 0.126 & 0.405 & 0.052 & 0.161 & 0.032 & 0.118 & 0.015 & 0.029 \\
\hline \multirow{6}{*}{ Point C } & \multirow{2}{*}{ North } & GPS + GLONASS & 0.089 & 0.432 & 0.048 & 0.152 & 0.033 & 0.097 & 0.013 & 0.035 \\
\hline & & GPS & 0.157 & 1.253 & 0.077 & 0.207 & 0.039 & 0.126 & 0.010 & 0.017 \\
\hline & \multirow{2}{*}{ East } & GPS+GLONASS & 0.130 & 0.413 & 0.073 & 0.261 & 0.041 & 0.097 & 0.026 & 0.059 \\
\hline & & GPS & 0.204 & 1.211 & 0.136 & 0.485 & 0.047 & 0.122 & 0.019 & 0.039 \\
\hline & \multirow{2}{*}{ Height } & GPS+GLONASS & 0.152 & 0.603 & 0.068 & 0.180 & 0.048 & 0.166 & 0.025 & 0.050 \\
\hline & & GPS & 0.225 & 1.391 & 0.103 & 0.357 & 0.058 & 0.146 & 0.031 & 0.056 \\
\hline
\end{tabular}

An analysis of the diagrams (Fig. 3, 4, 5, 6, 7, 8) has confirmed the results of postprocessing shown in Table 3. The diagrams of 2-dimentional coordinates (Fig. 3, 5, 7) are stretched in the east-west direction, which means greater coordinates determination deviations in this plane.
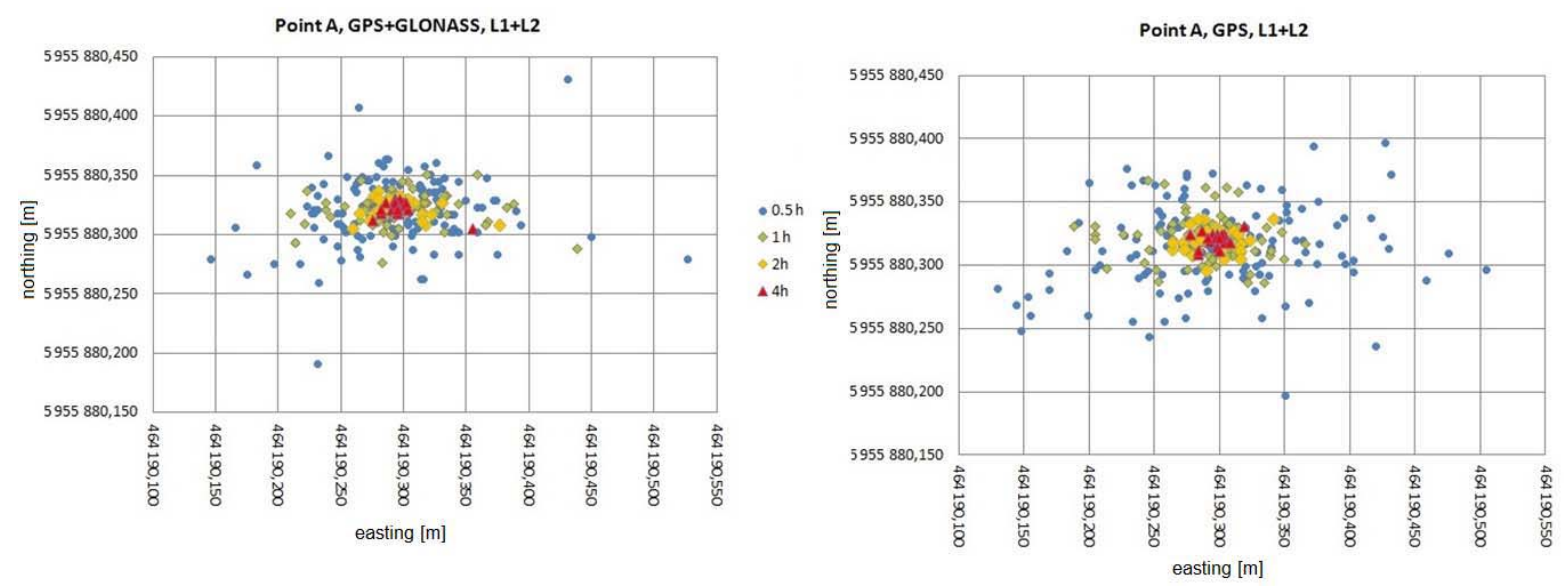

Fig. 3. UTM coordinates of point A obtained in the post-processing of observations at two frequencies 


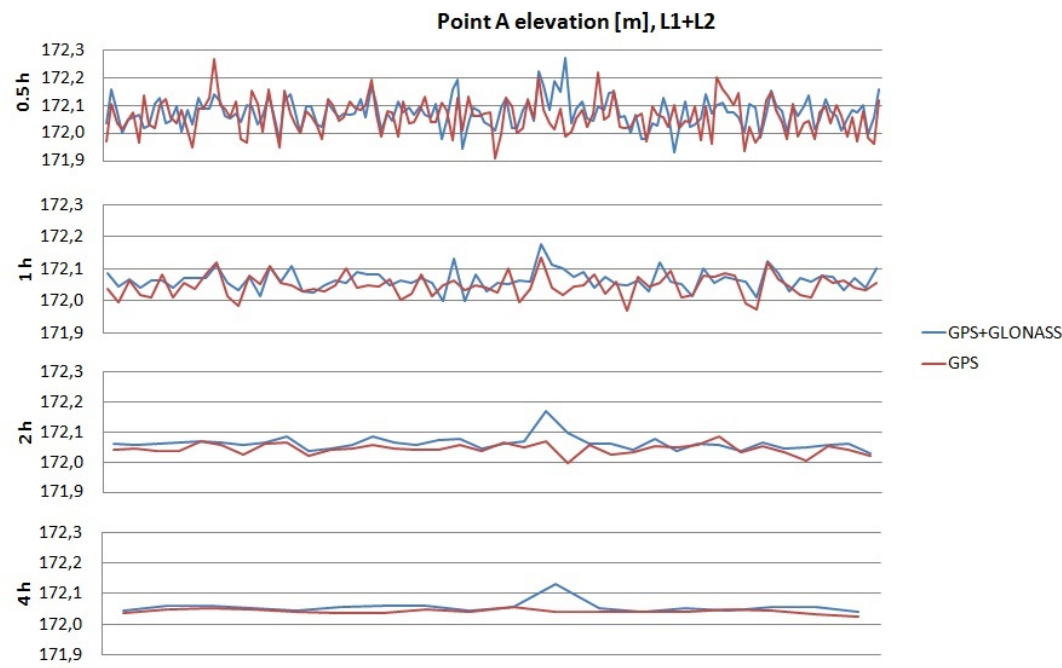

Fig. 4. Elevation of point A obtained in the post-processing of observations at two frequencies
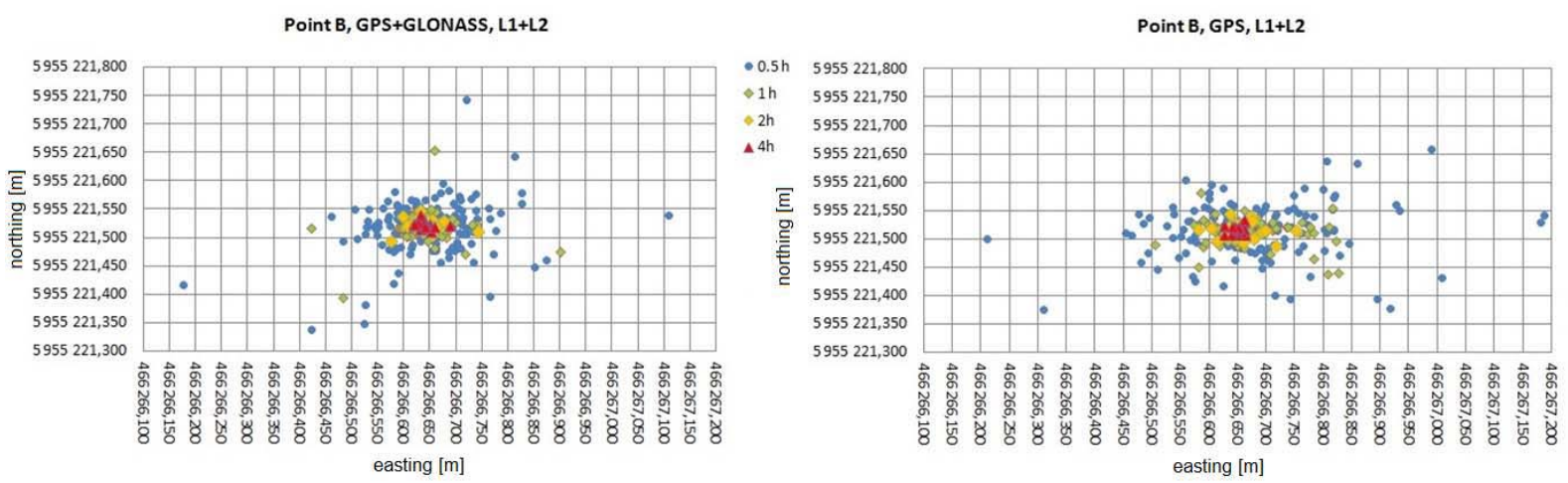

Fig. 5. UTM coordinates of point B from the post-processing of observations $L 1$ and $L 2$

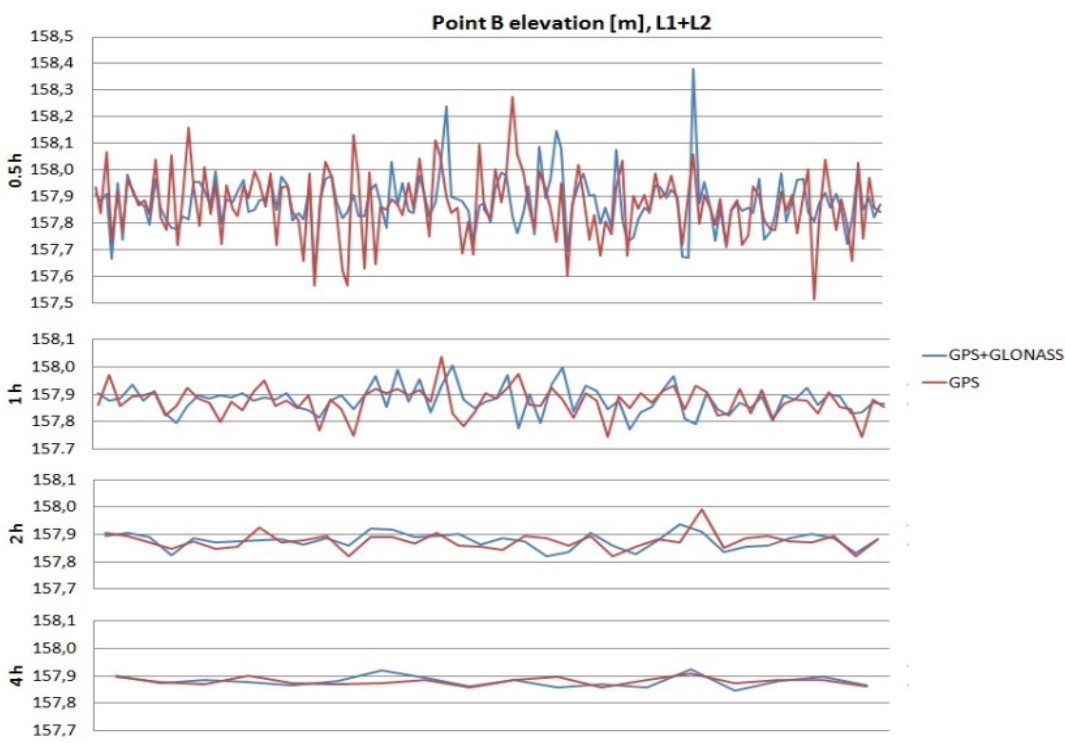

Fig. 6. Elevation of point B obtained in the post-processing of observations at two frequencies 

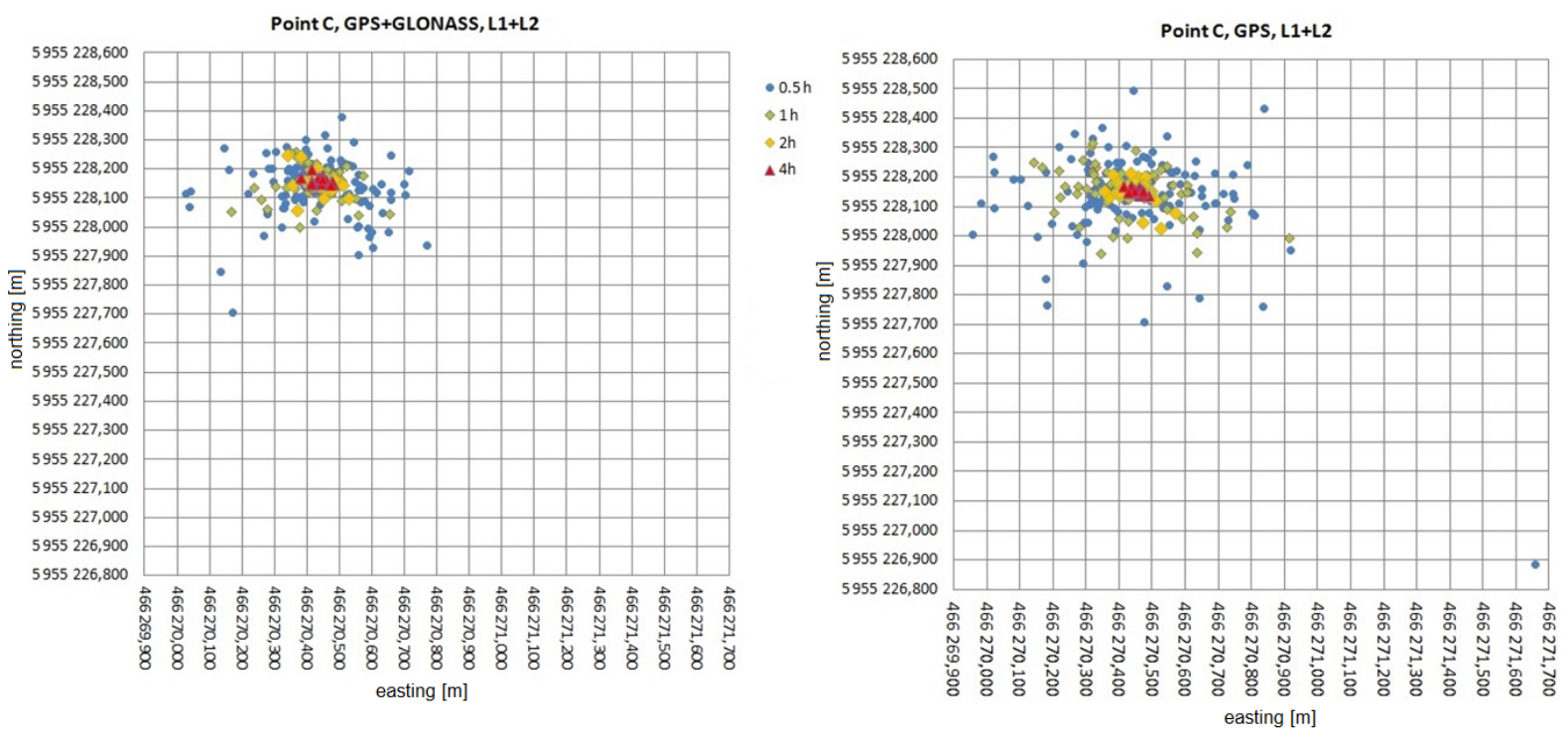

Fig. 7. UTM coordinates of point $\mathrm{C}$ obtained in the post-processing of observations at two frequencies

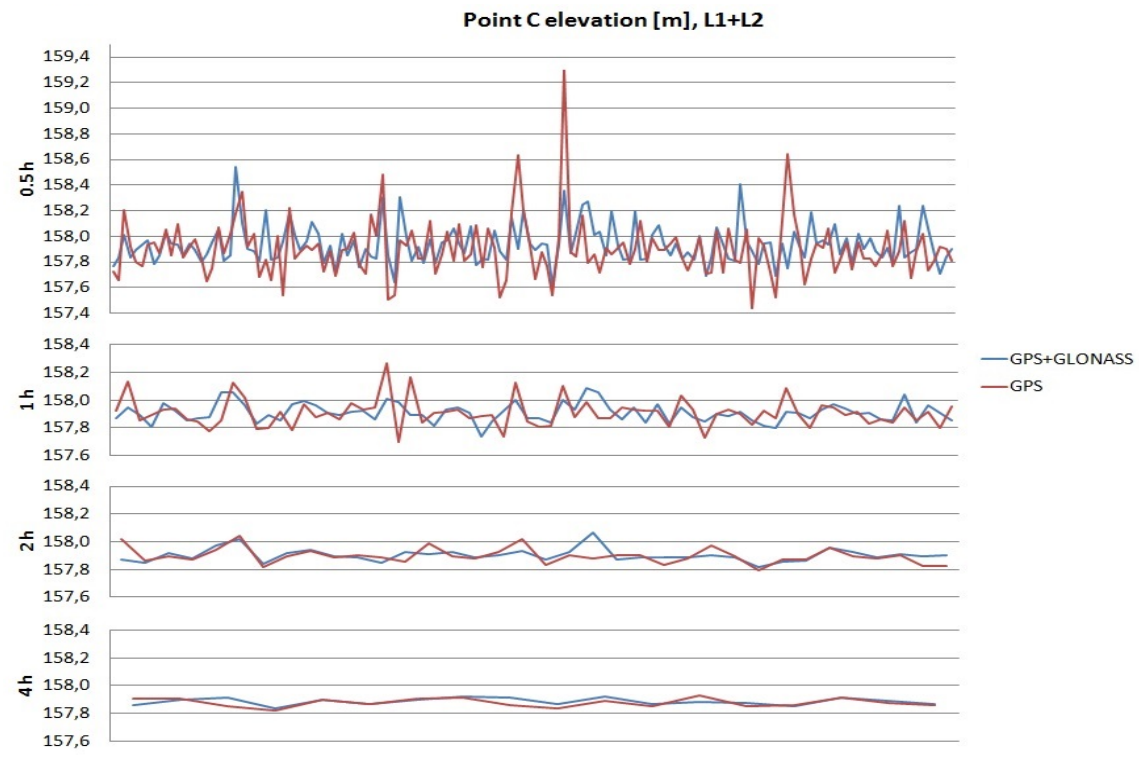

Fig. 8. Elevation of point $C$ obtained in the post-processing of observations at two frequencies

The impact of the length of observation session is clearly visible both on the diagrams of flat coordinates and of elevation (Fig. 3, 4, 5, 6, 7, 8). The determined positions are lessdispersed as the observation sessions become longer. The relationship becomes more apparent in the GPS+GLONASS for short sessions. The results presented in Fig. 4, 6, 8 show that adding observations from the GLONASS system did not significantly improve the precision of the elevation determination. A comparison of analogous diagrams made for points $\mathrm{A}, \mathrm{B}$ and $\mathrm{C}$ shows the significant effect of terrain obstacles, neighbouring on the measurement site, on the precision of determination of the three-dimensional position of a GNSS receiver.

Results of the post-processing of observations made at frequency L1 are shown in table 4. 
Tab. 4. Standard deviations and maximum deviations for the post-processing of $L 1$

\begin{tabular}{|c|c|c|c|c|c|c|c|c|c|c|}
\hline \multirow{2}{*}{\multicolumn{3}{|c|}{$L 1$}} & \multicolumn{2}{|c|}{$0.5 \mathrm{~h}$} & \multicolumn{2}{|c|}{$1 \mathrm{~h}$} & \multicolumn{2}{|r|}{$2 \mathrm{~h}$} & \multicolumn{2}{|c|}{$4 \mathrm{~h}$} \\
\hline & & & $\sigma$ & $\max \operatorname{dev}$ & $\sigma$ & $\max d e v$ & $\sigma$ & max dev. & $\sigma$ & max dev. \\
\hline \multirow{6}{*}{ Point A } & \multirow{2}{*}{ North } & GPS + GLONASS & 0.443 & 1.486 & 0.401 & 1.204 & 0.362 & 1.115 & 0.224 & 0.476 \\
\hline & & GPS & 0.427 & 1.189 & 0.386 & 1.095 & 0.316 & 0.859 & 0.207 & 0.409 \\
\hline & \multirow{2}{*}{ East } & GPS + GLONASS & 0.309 & 1.088 & 0.287 & 0.974 & 0.267 & 0.901 & 0.196 & 0.525 \\
\hline & & GPS & 0.234 & 0.691 & 0.207 & 0.590 & 0.190 & 0.468 & 0.155 & 0.286 \\
\hline & \multirow{2}{*}{ Height } & GPS+GLONASS & 0.942 & 3.665 & 0.877 & 2.940 & 0.714 & 2.439 & 0.613 & 1.670 \\
\hline & & GPS & 0.844 & 2.449 & 0.789 & 2.264 & 0.627 & 1.677 & 0.550 & 1.147 \\
\hline \multirow{6}{*}{ Point B } & \multirow{2}{*}{ North } & GPS + GLONASS & 0.539 & 1.693 & 0.454 & 1.154 & 0.360 & 1.101 & 0.207 & 0.386 \\
\hline & & GPS & 0.527 & 1.585 & 0.439 & 1.112 & 0.340 & 0.745 & 0.219 & 0.480 \\
\hline & \multirow{2}{*}{ East } & GPS + GLONASS & 0.334 & 1.047 & 0.307 & 0.981 & 0.278 & 0.877 & 0.200 & 0.458 \\
\hline & & GPS & 0.305 & 0.785 & 0.277 & 0.626 & 0.245 & 0.501 & 0.183 & 0.293 \\
\hline & \multirow{2}{*}{ Height } & GPS+GLONASS & 1.093 & 4.064 & 0.973 & 3.186 & 0.740 & 2.328 & 0.627 & 1.681 \\
\hline & & GPS & 0.936 & 2.802 & 0.828 & 2.066 & 0.606 & 1.382 & 0.513 & 1.023 \\
\hline \multirow{6}{*}{ Point C } & \multirow{2}{*}{ North } & GPS + GLONASS & 0.586 & 1.685 & 0.493 & 1.317 & 0.397 & 0.951 & 0.223 & 0.520 \\
\hline & & GPS & 0.668 & 3.169 & 0.470 & 1.433 & 0.399 & 1.051 & 0.302 & 0.860 \\
\hline & \multirow{2}{*}{ East } & GPS+GLONASS & 0.391 & 1.346 & 0.356 & 1.072 & 0.326 & 1.049 & 0.235 & 0.564 \\
\hline & & GPS & 0.353 & 2.044 & 0.284 & 0.951 & 0.258 & 0.673 & 0.196 & 0.322 \\
\hline & \multirow{2}{*}{ Height } & GPS+GLONASS & 1.304 & 5.093 & 1.098 & 4.431 & 0.874 & 2.044 & 0.629 & 1.482 \\
\hline & & GPS & 1.066 & 3.085 & 0.907 & 2.279 & 0.771 & 1.566 & 0.584 & 1.255 \\
\hline
\end{tabular}

Standard deviations in this variant are significantly higher than the deviations obtained in the post-processing of two-frequency measurements and they range from approx. $0.30 \mathrm{~m}$ for easting to over $1 \mathrm{~m}$ for elevation. Extending the measurement session did not significantly affect either this value or the maximum deviation of the coordinates from the "real" value. Adding the signals from the GLONASS system provided results which are in most cases worse than those obtained in post-processing of only GPS signals, for both standard and maximum deviation. As mentioned earlier this can be due to a lower accuracy of GLONASS corrections that have to be applied in post-processing. 

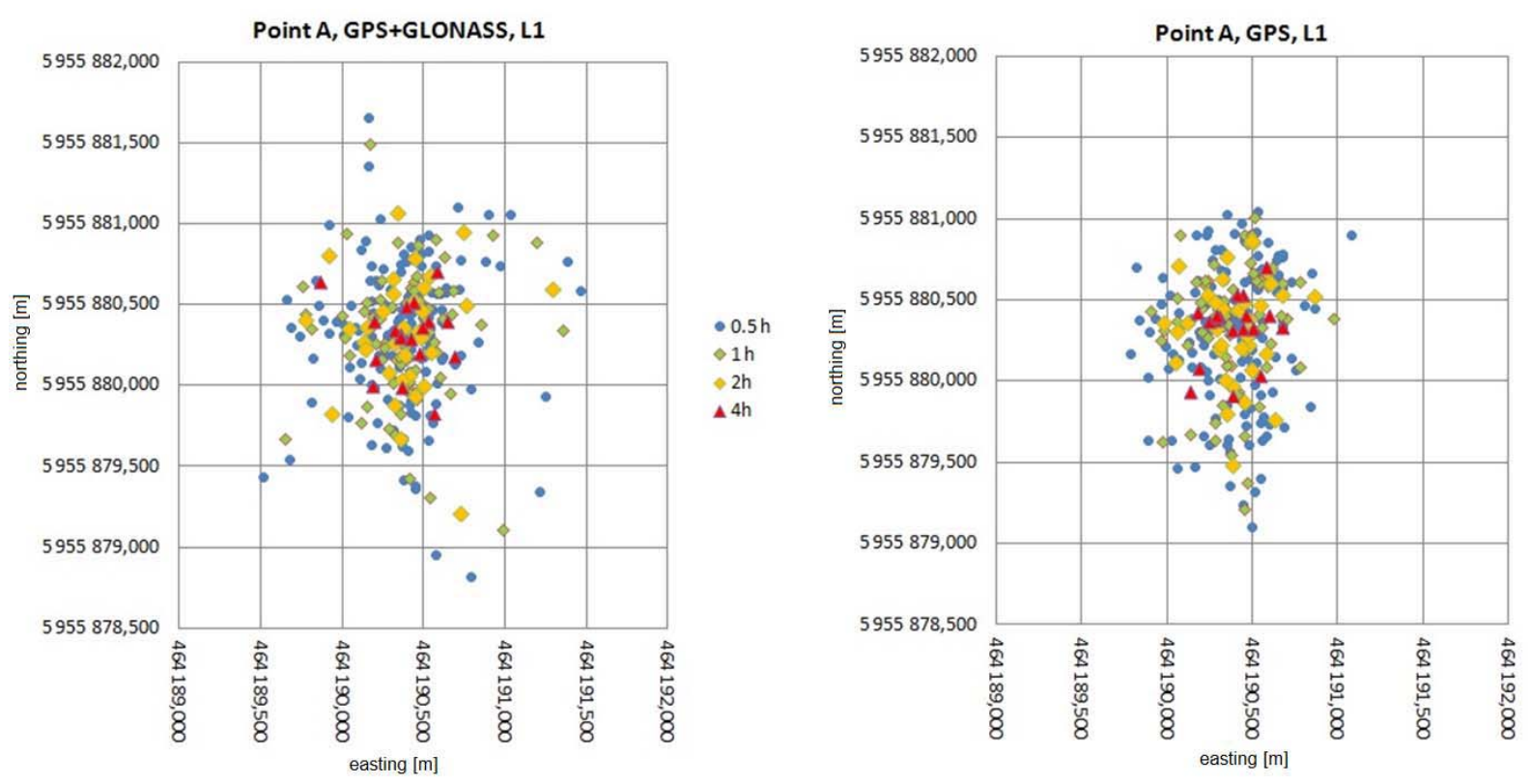

Fig. 9. UTM coordinates of point A obtained in the post-processing of observations at one frequency

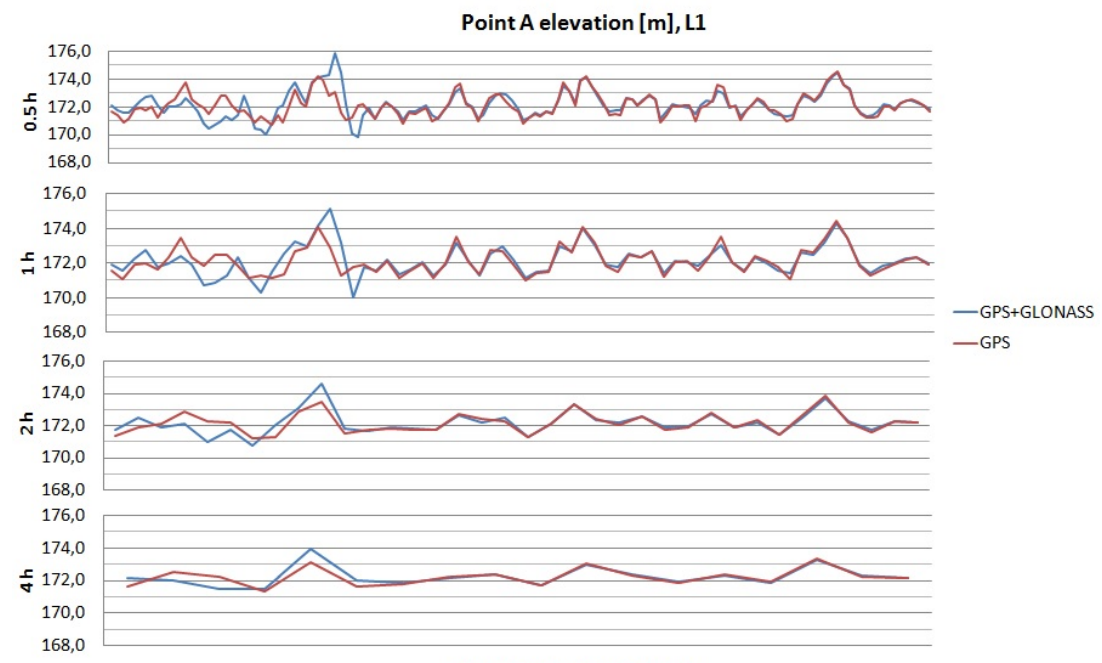

Fig. 10. Elevation of point A obtained in post-processing of observations at one frequency

An analysis of the diagrams 9, 10,11, 12, 13, 14 showing the results of determinations of coordinates in post-processing at one frequency has confirmed the conclusions based on the results shown in table 4 . The diagrams with horizontal coordinates are stretched in the northsouth direction. There is no visible improvement of the precision as the duration of sessions extends, and using signals from the GLONASS system in the post-processing worsened the results in almost all cases. The diagrams do not show any significant effect of terrain obstacles on the precision, as was the case in measurements performed at two frequencies. 

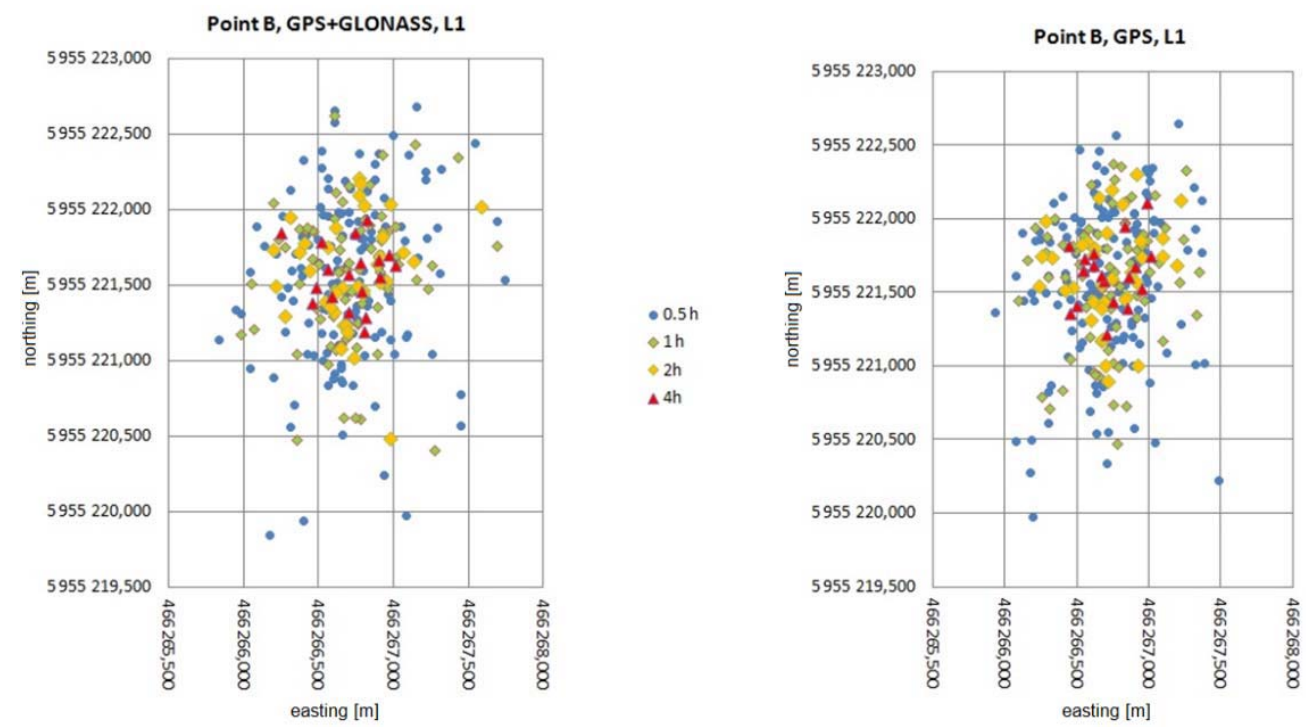

Fig. 11. UTM coordinates of point B obtained in the post-processing of observations at one frequency

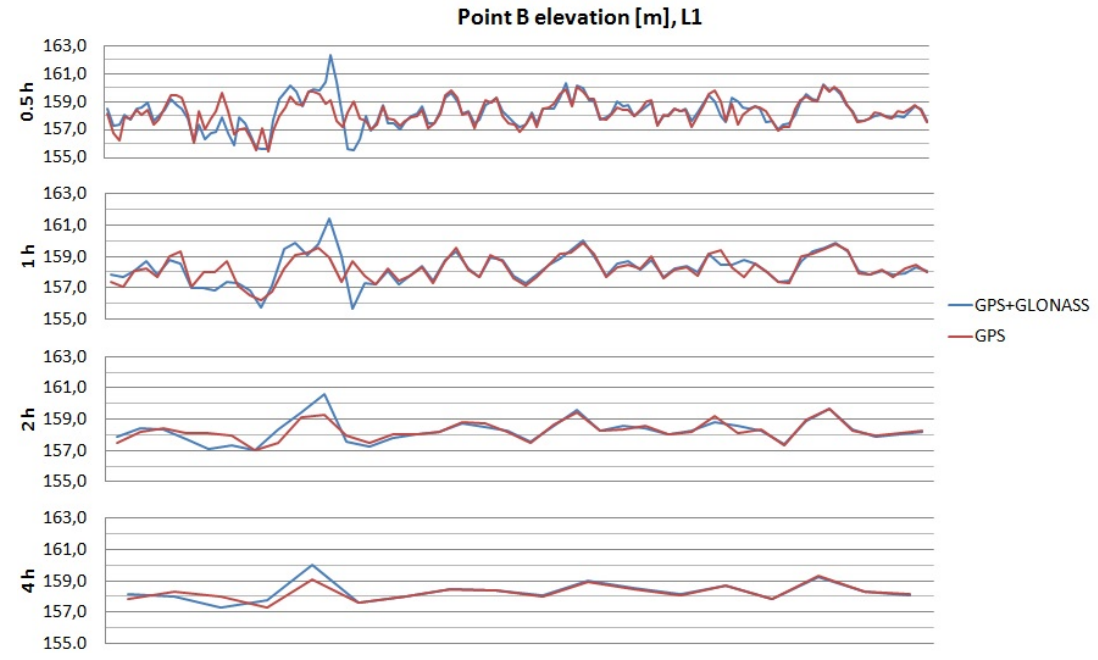

Fig. 12. Elevation of point $B$ obtained in the post-processing of observations at one frequency
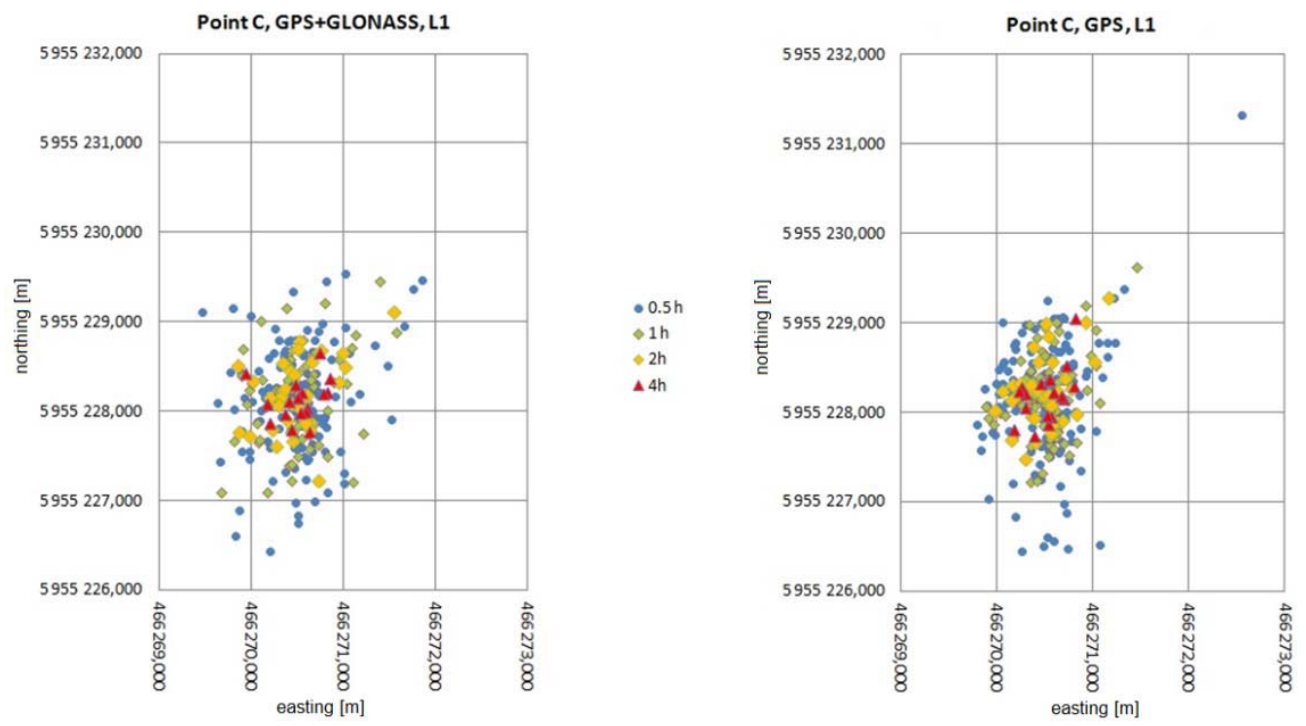

Fig. 13. UTM flat coordinates of point $\mathrm{C}$ obtained in the post-processing of observation $\mathrm{L} 1$ 


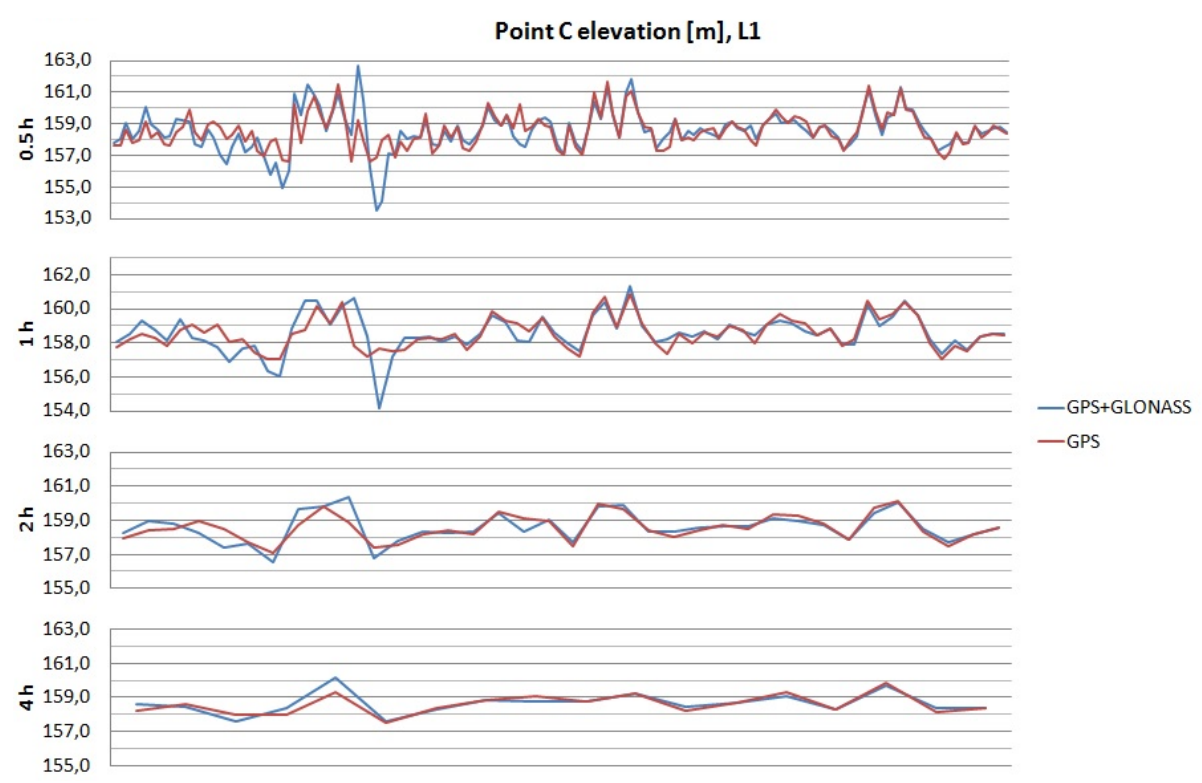

Fig. 14. Elevation of point $\mathrm{C}$ obtained in the post-processing of observations at one frequency

\section{SUMMARY AND CONCLUSIONS}

This paper examined the effect of the duration of a measurement session and of using observations from the GLONASS system on the measurement precision in different terrain conditions. An analysis was also performed of the precision of position determination from measurements performed at one or two frequencies and the possibility of automated postprocessing of observations with the CSRS-PPP service.

The results indicate that under good observation conditions (an unobscured horizon), with two observational frequencies, it is possible to achieve a precision of several centimetres after 2 hours of observation, and the standard and maximum deviations for the northing coordinate obtained in the post-processing of $L 1+L 2$ is approximately twice smaller than the easting and the elevation. This occurs in each time variant and it is manifest mainly at point A with the best measurement conditions. The addition of signals from the GLONASS system to the observations performed at two frequencies improved the results for short sessions, especially at points with limited visibility of the horizon $(\mathrm{B}, \mathrm{C})$; however the maximum deviations of coordinates from the "real" values increased in many cases (in four-hour sessions in almost all cases). For long sessions (4h) the standard deviations also slightly increased in the $G P S+G L O N A S S$ variant.

When observations were performed at one frequency for 30 minutes, the precision of 0.30 $-0.50 \mathrm{~m}$ was achieved for the horizontal coordinates and approx. $1 \mathrm{~m}$ for the elevation (standard deviation). The values improved slightly with increased duration of a session, but only four-hour observations reduced the standard deviation by half. The northing in this case had a greater deviation. Adding signals from the GLONASS system to the post-processing of observation in general worsened the results obtained in all three points (standard deviation), only slightly reducing the maximum deviation in some cases.

\section{LITERATURE:}

Alcay S., Inal C., Yigit C. O. (2012): Contribution of GLONASS Observations on Precise Point Positioning. FIG Working Week 2012 Rome, Italy, 6-10 May 2012.

Bisnath S., Gao Y., (2008): Current State of Precise Point Positioning and Future Prospects and Limitations. International Association of Geodesy Symposia 133. 
Bisnath S., Wells D., Dodd D. (2003): Evaluation of commercial carrier phase- based WADGPS services for marine applications. Proceedings of ION GPS/GNSS 9-12 September 2003, Portland, Oregon.

Cai Ch., Gao Y., (2007): Precise point positioning using combined GPS and GLONASS observations. Journal of Global Positioning Systems, 6, 1, 13-22.

Hofmann-Wellenhof, B., Lichtenegger, H. and Wasle, E. (2008): GNSS: Global Navigation Satellite Systems - GPS, GLONASS, GALILEO \& more, SpringerWienNewYork.

Huber K., Heuberger F., Abart Ch., Karabatic A., Weber R., Berglez P. (2010): PPP: Precise Point Positioning - Constraints and Opportunities. FIG Congress 2010, 11-16 April 2010 Sydney, Australia.

Kouba J., Héroux P., (2001): Precise point positioning using IGS orbit and clock products. GPS Solutions, 5, 2, 2001, 12-28.

Mireault Y., Tétreault P., Lahaye F., Héroux P., Kouba J. (2008): Online Precise Point Positioning. GPS World, September 2008, 59-64.

Rizos C., (2010): Making sense of the GNSS techniques. Manual of Geospatial Science and Technology, 2nd edition, Taylor \& Francis, 173-190.

Rizos C., Janssen V., Roberts C., Grinter T., (2012): Precise Point Positioning: Is the Era of Differential GNSS Positioning Drawing to an End? FIG Working Week 2012 Rome, Italy, 6-10 May 2012.

Stępniak K., Wielgosz P., Paziewski J., (2012): Badania dokładności pozycjonowania techniką PPP w zależności od długości sesji obserwacyjnej oraz wykorzystanych systemów pozycjonowania satelitarnego. Biuletyn WAT Vol. LXI, Nr 1, 429-450.

Van Der Marel H., De Bakker P., (2012): Single versus Dual-Frequency Precise Point Positioning. What are the tradeoffs between using L1-only and L1+12 for PPP? InsideGNSS, vol. 7, no. 4, 30-35.

Zumberge, J. F., M. B. Heflin, D. C. Jefferson, M. M. Watkins, and F. H. Webb (1997): Precise Point Processing for the Efficient and Robust Analysis of GPS Data from Large Networks. Journal of Geophysical Research: Solid Earth, 102(B3), 5005-5017.

Received: 2013-05-27,

Reviewed: 2013-06-21,

Accepted: 2013-07-04. 